\title{
Sepsis por Chromobacterium violaceum pigmentado y no pigmentado
}

\author{
Armando Guevara, Marlly Salomón, María Oliveros, Esmirna Guevara, Milarys Guevara y Zaida Medina
}

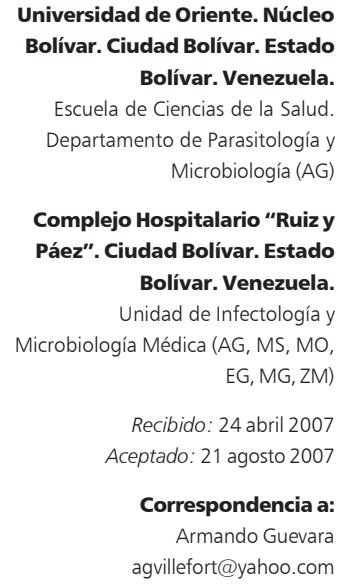

\section{Introducción}

C hromobacterium violaceum es un bacilo gram negativo, anaerobio facultativo, habitante común del suelo y agua en las regiones tropicales y subtropicales ${ }^{1-3}$ que se caracteriza por producir un pigmento, no difusible, llamado violaceína que da a las colonias un distintivo color violeta, aunque hasta $9 \%$ de las cepas aisladas no producen pigmento ${ }^{4,5}$. Este microorganismo es un patógeno oportunista que rara vez produce infección ${ }^{2-5}$. El primer caso de infección humana fue reportado en Malasia en 1927; desde entonces, han sido descritos algunos casos en forma esporádica ${ }^{4,6,7}$. La infección por esta bacteria ocurre, por lo general, luego de la exposición de heridas al agua o suelos contaminados ${ }^{3,6}$. Sin embargo, también hay reportes de cuadros diarreicos donde la vía de transmisión fue la ingestión de agua contaminada ${ }^{8,9}$. Presentamos un caso de sepsis cuyo punto de partida fue abdominal, aislándose, a partir de hemocultivos, cepas pigmentada y no pigmentada de $C$. violaceum.

\section{Caso clínico}

Paciente indígena, masculino, con 6 años de edad, sin antecedentes clínicos conocidos, residente de San José de Cayamá, población nativa ubicada al sur de Venezuela, en la selva amazónica. Fue admitido en el Complejo Hospitalario "Ruiz y Páez" en Ciudad Bolívar, Estado Bolívar, Venezuela, presentando fiebre y aumento de volumen en la región inguinal derecha, tras 16 días de evolución. El acompañante refería que el cuadro clínico se había iniciado con fiebre continua no cuantificada y dolor abdominal. El paciente permaneció en esa condición por 10 días, sin tratamiento médico debido a que residía en una zona sin asistencia sanitaria. En vista de que no hubo mejoría espontánea, los padres lo trasladaron a una misión religiosa cercana, donde se le administró ampicilina y acetaminofeno durante 6 días, sin remisión del cuadro clínico. Por tal motivo fue trasladado al centro hospitalario. El paciente y su acompañante negaron antecedentes de haber presentado náuseas, vómitos o diarrea, de haber tenido traumatismos o contacto con aguas estancadas. Tampoco infecciones recurrentes u otros factores predisponentes. El examen físico reveló una masa tumoral abdominal dolorosa en la fosa iliaca derecha e hipogastrio y aumento de volumen en la región inguinal derecha con signos inflamatorios. Los exámenes de laboratorio al ingreso mostraron: hemoglobina $8,8 \mathrm{gr} / \mathrm{dL}$, leucocitos $29.600 / \mathrm{mm}^{3}$, (neutrófilos $88 \%$, linfocitos $12 \%$ ), plaquetas en $378.000 / \mathrm{mm}^{3}$, velocidad de eritrosedimentación: $25 \mathrm{~mm} / \mathrm{h}$, creatininemia $0,6 \mathrm{mg} / \mathrm{dL}$, uremia 19 $\mathrm{mg} / \mathrm{dL}$, proteínas totales $7,1 \mathrm{gr} / \mathrm{dL}$. La Rx de tórax fue normal y la Rx simple de abdomen mostró asas intestinales ligeramente dilatadas con escasos niveles hidroaéreos. Fue ingresado con el diagnóstico de plastrón apendicular abscedado, recibió tratamiento antimicrobiano con metronidazol, ampicilina y amikacina durante 12 horas y posteriormente se realizó cirugía de urgencia para el drenaje del plastrón. Durante el acto 
operatorio se evidenció un absceso en el músculo psoas derecho, el que fuera drenado extrayéndose 300 $\mathrm{ml}$ de secreción purulenta amarillenta, no fétida, de la cual se envió una muestra para estudio bacteriológico. El procedimiento quirúrgico fue bien tolerado y con posterioridad a éste se cambió el tratamiento a vancomicina, ceftriaxona y metronidazol. La muestra de se-

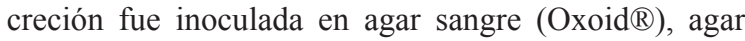
chocolate (Oxoid $\AA$ ) y agar McConkey (Oxoid $\AA)$. Luego de 18 horas de incubación a $35^{\circ} \mathrm{C}$, en microaerofilia, en todos los medios se aisló un bacilo gramnegativo, cuyas colonias eran de color violeta, diagnosticado como $C$. violaceum. La identificación de este microorganismo se realizó mediante métodos convencionales utilizando las pruebas bioquímicas señaladas en la Tabla 1. Se determinó la CIM para algunos $\beta$-lactámicos por epsilometría (E-test ${ }^{\circledR}, \mathrm{AB}$ biodisk), resultando sus-

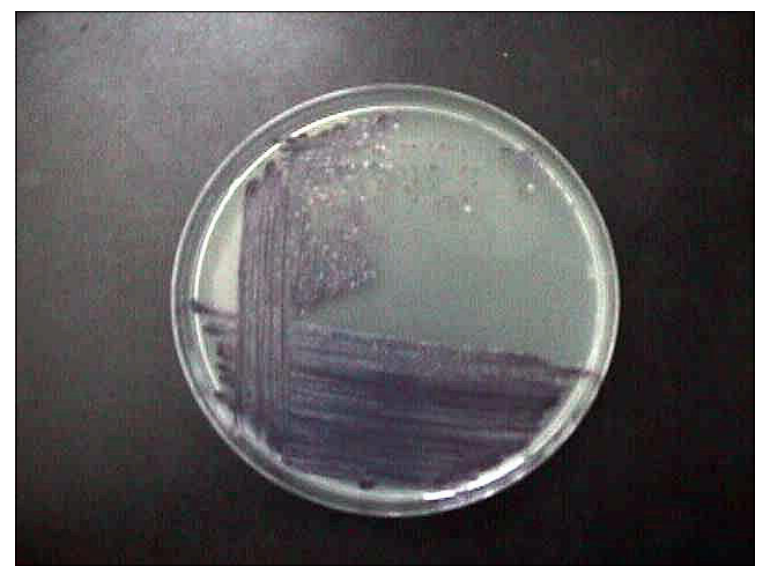

Figura 1. Subcultivo de hemocultivo en agar tripticasa soya donde se observan colonias pigmentadas y no pigmentadas.

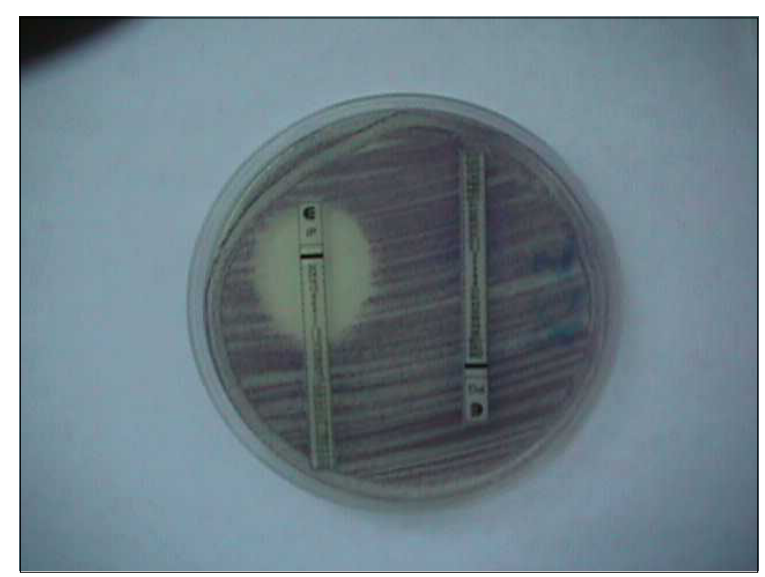

Figura 2. Determinación de la CIM para imipenem (izquierda) y penicilina (derecha) a través del método de difusión dilución (Etest ${ }^{\circledR}$. ceptible a los siguientes antimicrobianos: piperacilina (CIM $2 \mu \mathrm{g} / \mathrm{mL}$ ), piperacilina/tazobactan (CIM 2/4 $\mu \mathrm{g}$ / $\mathrm{mL}$ ), ceftazidima (CIM $4 \mu \mathrm{g} / \mathrm{mL}$ ), cefepima (CIM $6 \mu \mathrm{g} /$ $\mathrm{mL}$ ) e imipenem (CIM $1 \mu \mathrm{g} / \mathrm{mL}$ ) y resistente a penicilina $(\mathrm{CIM}>256 \mu \mathrm{g} / \mathrm{mL})$ y ceftriaxona $(\mathrm{CIM}>256 \mu \mathrm{g} / \mathrm{mL})$. Luego de conocer el patrón de susceptibilidad, en el cuarto día de hospitalización, se cambió el tratamiento antimicrobiano a imipenem y amikacina. Aun así, la condición del paciente se deterioró, persistiendo febril, por lo que en el quinto día de hospitalización se realizaron hemocultivos por el método convencional, en caldo BHI (Oxoid $®)$, los cuales fueron subcultivados en agar sangre y agar chocolate a las 24 horas de incubación, aislándose en esta oportunidad, cepas de C. violaceum pigmentadas y no pigmentadas en cada frasco, con un perfil de susceptibilidad a los antimicrobianos similar al del primer aislado. Las cepas fue-

\begin{tabular}{|c|c|c|c|c|}
\hline Prueba & $\begin{array}{c}\% \text { de } \\
\text { aislados } \\
\text { positivos* }\end{array}$ & $\begin{array}{c}\text { Cepa } \\
\text { pigmentada } \\
\text { de absceso } \\
\text { de psoas }\end{array}$ & $\begin{array}{c}\text { Cepa } \\
\text { pigmentada } \\
\text { de } \\
\text { hemocultivo }\end{array}$ & $\begin{array}{c}\text { Cepa no } \\
\text { pigmentada } \\
\text { de } \\
\text { hemocultivo }\end{array}$ \\
\hline Gas de glucosa & 0 & - & - & - \\
\hline Pigmentación violeta & 91 & + & + & - \\
\hline \multicolumn{5}{|l|}{ Acido de } \\
\hline D-glucosa & 100 & + & + & + \\
\hline D-manitol & 0 & - & - & - \\
\hline D-xilosa & 0 & - & - & - \\
\hline Lactosa & 0 & - & - & - \\
\hline Maltosa & 0 & - & - & - \\
\hline Sacarosa & 20 & - & - & - \\
\hline Reacción de catalasa & 97 & + & + & + \\
\hline Reacción de oxidasa & 67 & ND & ND & + \\
\hline Citrato de Simmons & 68 & + & + & - \\
\hline Hidrólisis de la urea & 5 & - & - & - \\
\hline Producción de indol & 21 & - & - & - \\
\hline Producción de $\mathrm{H}_{2} \mathrm{~S}$ & 0 & - & - & - \\
\hline Reacción de rojo de metilo & 37 & - & - & + \\
\hline Reacción de Voges Proskauer & 0 & - & - & - \\
\hline Crecimiento a $25^{\circ} \mathrm{C}$ & 100 & + & + & + \\
\hline Crecimiento a $42^{\circ} \mathrm{C}$ & 85 & + & + & + \\
\hline Hidrólisis de la esculina & 5 & - & - & - \\
\hline Lisina decarboxilasa & 0 & - & - & - \\
\hline Arginina dihidrolasa & 100 & + & + & + \\
\hline Ornitina decarboxilasa & 0 & - & - & - \\
\hline Crecimiento en $\mathrm{NaCl}$ al $6 \%$ & 0 & - & - & - \\
\hline
\end{tabular}


ron enviadas al Instituto Nacional de Higiene (centro nacional de referencia), confirmándose la identificación. El estado clínico del paciente continuó empeorando hasta llegar a shock séptico, falleciendo 9 días después de su ingreso.

\section{Discusión}

Chromobacterium. violaceum es un patógeno oportunista que puede causar infección, tanto en individuos sanos como en inmunocomprometidos, especialmente en pacientes con enfermedad granulomatosa crónica $^{6,10}$. En la actualidad se han reportado mas de 150 casos en todo el mundo, de los cuales 15 se presentaron en América Latina: 1 en Argentina ${ }^{11}$, 19 en Brasil $^{1,5,12,13}$, 1 en $\mathrm{Cuba}^{14}, 2$ en Panamá ${ }^{15,16}$ y 6 en Venezuela $^{17,18}$. La mayoría de los casos estudiados están asociados con lesiones de la piel y exposición al suelo $\mathrm{y}$ aguas estancadas ${ }^{3,6,10,19}$ pero también hay reportes asociados a ingestión de agua contaminada ${ }^{8}$, inmersión en estanques ${ }^{5,10}$, cuasi ahogo ${ }^{10,19}$, peritonitis ${ }^{20}$, osteomielitis y meningitis ${ }^{21,22}$. Las manifestaciones clínicas se inician tras un periodo de incubación variable que oscila entre 3 y 14 días, de acuerdo con el tipo de exposición ${ }^{10}$. Generalmente se presenta como una infección localizada en el sitio de inoculación, acompañada de fiebre, náuseas, vómitos y dolor abdominal intenso, con rápida progresión a la formación de múltiples abscesos en el hígado, pulmones, riñones y sepsis fulminante $e^{2,10,19,21}$. En este paciente, no se logró identificar la fuente de exposición ni la puerta de entrada del microorganismo pero, en vista de que era residente de una zona rural indígena, es posible que hubiese estado en contacto con agua o suelos contaminados y que se hubiera infectado a través de micro-abrasiones en la piel o de traumatismos punzo-cortantes, sin relevancia aparente en ese momento. La presentación clínica como un abdomen quirúrgico agudo es muy poco frecuente, así como el hallazgo de un absceso de psoas. A nuestro entender, este es el primer caso en que se reporta un absceso de este tipo producido por $C$. violaceum.

De los seis casos reportados anteriormente en Venezuela, tres fueron descritos en neonatos, uno en un niño de 6 meses y 2 en adultos. La presentación clínica fue variable: sepsis en dos casos (un adulto y un neonato), absceso hepático con antecedente reciente de celulitis abscedada en el sitio de una picadura de insecto en un caso (un adulto) y enfermedad diarreica en los casos restantes ${ }^{17,18}$.

Chromobacterium violaceum puede ser fácilmente aislado en los medios de cultivo de uso habitual, donde produce colonias de color violeta o púrpura, debido a la producción del pigmento violaceína ${ }^{3,6,7}$ lo cual facilita su identificación; sólo otras dos especies bacterianas producen pigmentos violáceos (Janthinobacterium lividum y Iodobacter fluviatilis) pero no son patógenas para el ser humano ${ }^{3}$. Sin embargo, existen cepas no pigmentadas, oxidasa positivas, que podrían confundirse con Aeromonas sp y Vibrio sp, de las cuales pueden diferenciarse por el perfil de fermentación de carbohidratos y la producción de lisina y ornitina decarboxilasa ${ }^{3,6,7}$. Las cepas no pigmentadas y oxidasa negativas podrían confundirse con Haemophilus aphrophilus o Pasteurella sp, pero es posible identificarlas correctamente por la producción de arginina dihidrolasa y su capacidad para crecer en agar salmonella-shigella ${ }^{6}$. En la Tabla 1 se muestran las pruebas bioquímicas usadas para la identificación de C. violaceum.

Debido a la publicación de la secuencia completa del genoma de $C$. violaceum, en la actualidad se conocen algunos de su mecanismos de virulencia como la producción de hemolisinas, citolisinas, elastasas, proteasas, factores de adhesión, superoxido dismutasa y violaceína ${ }^{4}$. La violaceína ha despertado mucho interés en la comunidad científica, ya que posee propiedades antibacterianas, antiparasitarias y antitumorales ${ }^{4,23,24}$. El papel físiológico exacto de esta sustancia no se conoce; se ha postulado que podría esta implicada en la protección de la bacteria contra la radiación solar o en la regulación de la cantidad de triptófano en el medio, ya que este aminoácido en elevadas concentraciones, es tóxico para la bacteria. También se ha sugerido que la violaceína juega un papel importante en el quorum sensing de $C$. violaceum, ya que su producción es inducida por la N-hexaonil homoserina lactona (HHL), molécula señal del quorum sensing, cuya concentración en el medio estimula el aumento de la población bacteriana ${ }^{24}$. El posible rol de la violaceína en la patogénesis humana está relacionado con sus propiedades citotóxicas; no obstante, la presencia de este pigmento por sí solo no explica la virulencia de este microorganismo ya que también se han comunicado infecciones graves producidas por cepas no pigmentadas de $C$. violaceum ${ }^{4,6,25}$. Este es el primer caso reportado en el cual, de una misma muestra biológica se aíslan cepas pigmentadas y no pigmentadas.

El tratamiento de las infecciones por $C$. violaceum puede ser complicado pues este microorganismo se caracteriza por presentar resistencia a muchos de los antimicrobianos de uso rutinario como penicilinas y cefalosporinas. Esto puede ser explicado por la presencia de genes que codifican mecanismos de resistencia como bombas de eflujo, serino $\beta$-lactamasas y metalo $\beta$-lactamasas ${ }^{26,27}$. En la mayoría de los casos estudiados, $C$. violaceum ha resultado ser susceptible in vitro a las fluoroquinolonas, carbapenémicos, 
aminoglucósidos, piperacilina, cotrimoxazol y cloranfenicol, con resultado variable para las cefalosporinas ${ }^{2,6,7,13,19,21,22}$. En nuestro caso, los microorganismos aislados fueron totalmente resistentes a ceftriaxona pero susceptibles a ceftazidima y cefepima.

En el manejo del paciente infectado por C. violaceum, la sospecha clínica, el diagnóstico precoz y el tratamiento oportuno y adecuado son aspectos relevantes para garantizar la supervivencia ${ }^{1,5,7,10,19,21}$. En el caso presentado, hubo un retraso de 20 días para iniciar la terapéutica adecuada; esto se debió en primer lugar al hecho de que el paciente habitaba en una comunidad indígena remota, ubicada en la amazonía venezolana, donde no se cuenta con asistencia médica, a que la infección por $C$. violaceum es muy poco frecuente y el patógeno, así como su posible perfil de susceptibilidad, es desconocido por la mayoría de los médicos. Otro factor que incidió en este aspecto fue la presentación clínica como una masa tumoral en la fosa iliaca derecha e hipogastrio, lo cual orienta principalmente hacia otros procesos infecciosos ya que el absceso del músculo psoas es una entidad muy poco frecuente. Es muy probable que la tardanza en la administración de antibioterapia adecuada, aunada a los mecanismos de virulencia de C. violaceum, hayan condicionado la escasa respuesta clínica que presentó el paciente conduciéndolo al shock séptico y a la muerte.
En conclusión, podemos decir que las infecciones por $C$. violaceum son inusuales y su diagnóstico requiere un alto índice de sospecha, especialmente si el paciente presenta antecedentes de actividades al aire libre como contacto con aguas estancadas, ríos, lagunas y traumatismos punzo-cortantes. El tratamiento adecuado debe ser instaurado a la brevedad posible en vista de la rápida progresión y su elevada letalidad.

\section{Resumen}

La sepsis por Chromobacterium violaceum es un cuadro clínico rara vez reportado y asociado con una elevada letalidad. Comunicamos un caso fatal de sepsis en un niño indígena venezolano con 6 años de edad, quien presentó fiebre y aumento de volumen en la región inguinal derecha y que fuera inicialmente diagnosticado como plastrón apendicular abscedado. La cirugía de apendicetomía reveló un absceso en el músculo psoas derecho, del cual se aisló una cepa pigmentada de $C$. violaceum, mientras que a partir de hemocultivos se aislaron cepas pigmentada y no pigmentada, simultáneamente, del mismo agente. Se administró tratamiento con imipenem y amikacina pero su condición se deterioró y falleció a los 9 días de su ingreso.

\section{Referencias}

1.- Martínez R, Velludo M A, dos Santos V R, Dinamarca P B. Chromobacterium violaceum infection in Brazil. A case report. Rev Inst Med Trop S Paulo 2000; 42: 111-3.

2.- Chang-Hua C, Li-Chen L, Chun-Eng L, Tzuu-Guang Y. Chromobacterium violaceum bacteremia: a case report. J Microbiol Immunol Infect 2003; 36: 141-4.

3.- Grier D D, Qui J, Rand K, Donnelly W. A 13-year-old boy with a 2-day history of fever, vomiting and mental status changes. Arch Pathol Lab Med 2004; 128: e131e132.

4.- Alves C F, Carvalho C M B, Santos F R, Gazzinelli R T, Oliveira S C, Azevedo V, et al. Chromobacterium violaceum genome: molecular mechanism associated with pathogenicity. Genet Mol Res 2004; 3: 148-61.

5.- Siqueira I C, Dias J, Ruf H, Ramos E A, Pires E A, Rolim A, et al. Chromobacterium violaceum in siblings, Brazil. Emerg Infect Dis 2005; 11: 1443-5.
6.- Lee J, Kim J S, Nahm C H, Choi J W, Kim J, Pai S H, et al. Two cases of Chromobacterium violaceum infection after injury in a subtropical region. J Clin Microbiol 1999; 37: 2068-70.

7.- Ray P, Sharma J, Marak R S, Singhi S, Taneja N, Garg R K, et al. Chromobacterium violaceum septicaemia from north India. Indian J Med Res 2004; 120: $523-6$.

8.- Dromigny J A, Fall A L, Diouf S, PerrierGros-Claude J D. Chromobacterium violaceum: a case of diarrhea in Senegal. Pediatr Infect Dis J 2002; 21: 573-4.

9.- Ballal M, Kini, P, Rajeshwari D, Shivananda P G. Chromobacterium violaceum diarrhea. Indian J Pediatr 2000; 67: $388-9$

10.- Dias J P, Silvany C, Saraiva M M, Ruf H R, Guzman J D, Carmo E H. Cromobacteriose em Ilhléus, Bahia: investigação epidemiológica clinica e laboratorial. Rev Soc Br Med Trop 2005; 38: 503-6.

11.- Kaufman S C, Ceraso D, Schugurensky A. First case report from Argentina of fatal septicemia caused by Chromobacterium violaceum. J Clin Microbiol 1986; 23: 956-8.

12.- Peretrillo V F, Severo V, Santos M M, Edelweiss E L. Recurrent infection with Chromobacterium violaceum: first case report from South America. J Infect 1984; 9: $167-9$

13.- Sampaio-Sa M, Amorin L R, Casela M, Brites C. Frequent isolation of Chromobacterium violaceum in patients with lifethreatening diseases, in Bahia, Brazil. Progam and abstracts of $45^{\text {th }}$ Interscience Conference on Antimicrobial Agents and Chemotherapy. Washington DC. 16 a 19 de diciembre de 2005. Abstract K1555.

14.- Machin C, Ley M, Torres L. Infección por Chromobacterium violaceum: presentación de un caso con evolución fatal. Rev Cub Med Trop 1986; 38: 353-7.

15.- Marshall B, Caballero E, Medina E, Mendoza N, Pinilla L, Talavera D, et al. Septicemia fatal causada por Chromobacterium violaceum: informe de un caso; Complejo Hospitalario Metropolitano, 1986. Rev Med Caja Seguro Soc 1988; 20: 98-100.

16.- Ríos C, Delgado S, Sistemas O. Septicemia 
por Chromobacterium violaceum. Rev Hosp Niño (Panamá) 1985; 5: 22-5.

17.- Darricarrere R, Urrestarazu M, Carvajal Z, Uzcátegui Z, Taibo M, Padrón A, et al. Infecciones causadas por agentes oportunistas: Corynebacterium $J K$ y Chromobacterium violaceum. Arch Hosp Vargas 1986; 28: 151-4.

18. - Pineda M, Vargas J, Luengo H. Chromobacterium violaceum. The first reports in Venezuela and literatura review. $9^{\text {th }}$ International Congress on Infectious Diseases. Buenos Aires 10 al 13 de abril de 2000. Resumen 16.002.

19.- Teoh A Y, Hui M, Ngo K Y, Wong J, Lee K F, Lai P B. Fatal septicaemia from Chromobacterium violaceum: case reports and review of the literature. Hong Kong Med J 2006; 12: 228-31.

20.- Watine J, Courtade A, Pham E, Lievrouw C,
Dobourdieu B, Guèrin B, et al. Chromobacterium violaceum peritonitis: Case report and literature review. Ann Biol Clin (Paris) 2006; 64: 327-30.

21.- Midani S, Rathore M. Chromobacterium violaceum infection. South Med J 1998; 91: 464-6.

22.- Moore C, Lane J, Stephens J. Successful treatment of an infant with Chromobacterium violaceun sepsis. Clin Infect Dis 2001; 32: e107-e110.

23.- de Carvalho D D, Costa F T, Duran N, Haun M. Cytotoxic activity of violacein in human colon cancer cells. Toxicol In Vitro 2006; 20: 1514-21.

24.- Pitlovanciv A K, Caris M E, Marques L, Curi R, Vasconcellos R. Condições de cultivo e produção de pigmentos por Chromobacterium violaceum. Biotemas 2006; 19: 13-8.
25.- Millar D P, Blevins W T, Steele D B, Stowers M D. A comparative study of virulent and avirulent strains of Chromobacterium violaceum. Can J Microbiol 1988; 34: 249-55.

26.- Fantinatti-Garboggini F, Almeida R, Portillo Vdo A, Barbosa T A, Trevilato P B, Neto $\mathrm{C}$ E, et al. Drug resistance in Chromobacterium violaceum. Genet $\mathrm{Mol}$ Res 2004; 3: 134-47.

27.- Docquier J D, Longatti A, Amicosante G, Frere J M, Rossolini G M. Post-genomic identification and characterization of a new subclase B2 metallo- $\beta$-lactamase encoded by the chromosome of Chrombacterium violaceum. Program and Abstracts of $44^{\text {th }}$ Interscience Conference on Antimicrobial Agents and Chemotherapy. Washington DC, 30 de octubre al 2 de noviembre de 2004. Abstract C1289. 